\title{
Morphometric parameters of the internal organs of a water deer (Hydropotes inermis Swinhoe 1870)
}

\author{
E. N. Lyubchenko ${ }^{1, *}$, I. P. Korotkova ${ }^{1}$, R.A. Zhilin ${ }^{1}$, A. A. Kozhushko ${ }^{1}$, E. A. Korotkov ${ }^{1}$, \\ and M. Yu.Schelkanov ${ }^{2,3,4}$ \\ ${ }^{1}$ Primorsk State Agricultural Academy, Ussuriisk, 692510, Russia \\ ${ }^{2}$ Federal Scientific Center of the East Asia Terrestrial Biodiversity, Far Eastern Branch of the Russian \\ Academy of Sciences, Vladivostok, 690022, Russia \\ ${ }^{3}$ National Scientific Center of Marine Biology, Far Eastern Branch of the Russian Academy of \\ Sciences, Vladivostok, 690041, Russia \\ ${ }^{4}$ Far Eastern Federal University, Vladivostok, 690922, Russia
}

\begin{abstract}
The paper presents the results of a morphometric study of the internal organs of a water deer (Hydropotes inermis Swinhoe 1870) found in the southern part of the Primorsky Krai of Russia. For the first time, the linear and weight parameters were determined, the morphological features of the internal organs of the water deer were described.
\end{abstract}

\section{Introduction}

Water deer (Hydropotes inermis Swinhoe 1870) was once widespread around the entire Yellow Sea - from the western coast of the Korean Peninsula to the lower reaches of the Yangtze River [11, 14]. But by the middle of the last century, only two habitats remained the Chinese water deer (H. i. Inermis) in the Shanghai region in southern China with a population of no more than 10,000 individuals [13], and the Korean water deer (H. $i$. Argyropus) on border of South and North Korea [12]. There is information about the transitions of water deer from North Korea to China [3]. In 2019, in the Land of the Leopard National Park, a camera trap recorded a "swamp musk deer", which, according to experts, turned out to be a water deer [3]. This small deer of an unusual appearance simultaneously resembles a Siberian roe deer (Capreolus pygargus Pallas 1771) and a musk deer (Moschus moschiferus L., 1758).

In February 2020, in the Khasansky District of the Primorsky Krai, a corpse of a water deer was found [9], which received the identifier FEBBM WD-2 in the Far Eastern Bank of Biological Materials from specially protected animals and plants [10]. This made it possible to conduct a more detailed study of the water deer, in particular, linear and weight parameters of internal organs, the results of which are presented in this work.

\footnotetext{
* Corresponding author: adorob@mail.ru
} 


\section{Materials and methods}

The corpse of an animal with a bullet wound was found on February 1, 2020 in a forest 3 $\mathrm{km}$ southeast of the village of Khasan (Khasansky District, Primorsky Krai). In accordance with the Ministry of Forestry and Wildlife Protection of the Primorsky Krai, on February 2, 2020, the animal corpse was delivered for veterinary examination to the Diagnostic Center of Animal Diseases of the Animal Science and Veterinary Medicine Institute of the Primorsky State Agricultural Academy. Determination of the species, sex and age of the animal was carried out by comparison with literature sources (Krivosheev, 1984) [7]. The identification of the taxonomic position was carried out according to the Sokolov scheme (1979) [8], the sex and age were determined according to Salovarov and Vodopyanov (2001) [2].

The weight of the animal was determined using a Caston-I electronic crane scale (CAS Corp., Republic of Korea) with a measurement scale of up to $500 \mathrm{~kg}$ and a graduation of $0.1 \mathrm{~kg}$. The postmortem examination was carried out using the method of partial evisceration, the objects of study were internal organs, they were separated from the corpse according to the method proposed by N.S. Kukharenko and A.O. Fedorova (2015) [5]. For topographic studies, the lateral walls of the chest and abdominal cavities were removed together with the diaphragm; bone markers were used to describe the localization of organs. Morphometric studies consisted of a description of internal organs (shape, color, consistency), linear and weight parameters [6].

Linear measurements of organs were carried out using a flexible measuring tape (with an accuracy of $1 \mathrm{~mm}$ ) and a steel caliper (Shock-Proof with an accuracy of $0.5 \mathrm{~mm}$ ). Organ weights were obtained using a Delta KCE-40-21 electronic balance with an accuracy of $0.001 \mathrm{~g}$. Before weighing, the stomach and intestines were carefully separated from the mesentery, and the length, width of the stomach and the length of each part of the intestine were measured with a measuring tape.

During the postmortem examination, photographs were taken using a SONY Alpha camera in order to fix the individual studied phenomena and objects, to obtain visual material [4].

\section{Research results}

In the course of the work carried out, we found that the animal under study was the Water deer (Hydropotes inermis) belonging to the order Artiodactyla, the family Cervidae, the subfamily Hydropotinae, and the genus Hydropotes. This animal is represented by a female, estimated age - 2-2.5 years.

The water deer is not a large animal, it has a short body with a small elongated head, large eyes and wide ears, the forelimbs are shorter than the hind ones, and the tail is small. The weight of the animal is $19.8 \mathrm{~kg}$, the oblique body length is $75.0 \mathrm{~cm}$, the length of the body from the tip of the nose to the root of the tail is $105.0 \mathrm{~cm}$, the height at the withers is $62.0 \mathrm{~cm}$, the girth of the chest is $65.0 \mathrm{~cm}$.

Fatness is good, the skin is elastic, gray in color, the skin fold is well straightened.

Subcutaneous fat of light gray color with areas of dark gray color, dense consistency, did not crumble when crushed, in an insignificant amount was located in the form of layers on the costal wall and on the peritoneum.

The muscles are red with a brownish tinge, dry, soaked in blood and crushed at the sites of bone fractures. This water deer had 13 pairs of ribs.

Fat deposits of light gray color were found on the pericardium of the heart. At the base of the heart, epicardial fat deposits are light gray. The apex of the heart is pointed, the 
coronary vessels are well expressed, moderately filled with blood. Heart weight $-0.252 \mathrm{~kg}$. The morphometric characteristics of the heart of a water deer are shown in table 1.

Table 1. Morphometric characteristics of the heart of the water deer.

\begin{tabular}{|c|c|c|c|c|c|}
\hline No. & Indicators & Appearance & 吾 & $\underbrace{2}$ & 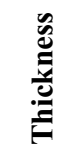 \\
\hline 1 & Heart, cm & Spherical shape, organ index $-76.7 \%$. & 9.0 & 6.9 & 5.9 \\
\hline 2 & Right atrium, $\mathrm{mm}$ & Oval, with a fringed edge & 45.6 & 30.9 & - \\
\hline 3 & Left atrium, $\mathrm{mm}$ & Oval, with a fringed edge & 38.6 & 28.3 & - \\
\hline 4 & $\begin{array}{l}\text { Right ventricular } \\
\text { wall, } \mathrm{mm}\end{array}$ & $\begin{array}{l}\text { Relatively thin, dense. Fleshy trabeculae of } \\
\text { the inner surface are smoothed, the greatest } \\
\text { number and severity in the area of the } \\
\text { papillary muscle. They are less pronounced } \\
\text { on the medial wall. }\end{array}$ & - & - & 6.5 \\
\hline 5 & $\begin{array}{l}\text { Left ventricular } \\
\text { wall, } \mathrm{mm}\end{array}$ & $\begin{array}{l}\text { Thickened, dense. Fleshy trabeculae are } \\
\text { concentrated in the apical region on all three } \\
\text { walls (cranial, caudal, medial), in the form of } \\
\text { well-defined muscle ridges. }\end{array}$ & - & - & 14.2 \\
\hline \multirow[t]{4}{*}{6} & $\begin{array}{l}\text { The papillary } \\
\text { muscles of the } \\
\text { right ventricle, } \\
\text { mm: }\end{array}$ & $\begin{array}{l}\text { Well expressed. Septal (small and } \\
\text { hyparterial) are smaller in size than parietal } \\
\text { (large). }\end{array}$ & - & - & - \\
\hline & - large & $\begin{array}{l}\text { Large, complex indefinite shape, with three } \\
\text { heads. }\end{array}$ & 8.4 & 16.4 & - \\
\hline & - small & Cone-shaped, with one head. & 6.7 & 7.07 & - \\
\hline & - hyparterial & Complex indefinite shape, with two heads. & 7.2 & 6.2 & - \\
\hline \multirow[t]{4}{*}{7} & $\begin{array}{l}\text { Right ventricular } \\
\text { cusps, mm: }\end{array}$ & $\begin{array}{l}\text { The cusps have a weakly pronounced border } \\
\text { between themselves, determined by } \\
\text { commissures. The longest is parietal, and the } \\
\text { shortest is septal. The width of the bundles } \\
\text { varies widely. }\end{array}$ & - & - & - \\
\hline & - corner & Medium length and widest. & 25.2 & 6.1 & 0.2 \\
\hline & - parietal & Longest, medium width. & 27.5 & 4.9 & 0.1 \\
\hline & - septal & The shortest and narrowest. & 24.3 & 3.6 & 0.2 \\
\hline \multirow[t]{3}{*}{8} & $\begin{array}{l}\text { Septomarginal } \\
\text { trabeculae of the } \\
\text { right ventricle, } \\
\text { mm: }\end{array}$ & $\begin{array}{l}\text { Represented by a cranial septomarginal } \\
\text { trabecula. }\end{array}$ & & & \\
\hline & - cranial & Of the tendinous type & 20.2 & 0.7 & 0.7 \\
\hline & - caudal & Not expressed & - & - & - \\
\hline \multirow[t]{3}{*}{9} & $\begin{array}{l}\text { The papillary } \\
\text { muscles of the left } \\
\text { ventricle, } \mathrm{mm} \text { : }\end{array}$ & $\begin{array}{l}\text { There are two main papillary muscles, no } \\
\text { additional ones. }\end{array}$ & - & - & - \\
\hline & - subatrial & Powerful, cylindrical, one head. & 15.5 & 15.1 & - \\
\hline & - cushion & Powerful, cylindrical, one head. & 14.4 & 10.4 & - \\
\hline 10 & $\begin{array}{l}\text { Left ventricular } \\
\text { cusps, mm: }\end{array}$ & $\begin{array}{l}\text { The cusps have a weakly pronounced border } \\
\text { between themselves, determined by } \\
\text { commissures. The longest is septal, and the } \\
\text { shortest is septal. The cusp width varies } \\
\text { slightly. }\end{array}$ & - & - & - \\
\hline & - parietal & Relatively short and narrow. & 32.3 & 5.6 & 0.2 \\
\hline & - septal & Relatively long and wide. & 41.2 & 6.1 & 0.2 \\
\hline
\end{tabular}




\begin{tabular}{|l|l|l|l|l|l|}
\hline 11 & $\begin{array}{l}\text { Septomarginal } \\
\text { trabeculae of the } \\
\text { left ventricle, } \mathrm{mm}:\end{array}$ & $\begin{array}{l}\text { Well expressed, of the tendinous type, with } \\
\text { branching at the point of attachment. }\end{array}$ & - & - & - \\
\hline & - cranial & $\begin{array}{l}\text { Located between the base of the subatrial } \\
\text { papillary muscle and the interventricular } \\
\text { septum. }\end{array}$ & 21.5 & 0.6 & 0.6 \\
\hline & - caudal & $\begin{array}{l}\text { Located between the base of the papillary } \\
\text { cushion muscle and the interventricular } \\
\text { septum. }\end{array}$ & 25.9 & 0.3 & 0.3 \\
\hline
\end{tabular}

Thus, the heart of the studied water deer of the subspecies Hydropotes inermis argyropus was spherical in shape, distinguished by a strong left ventricle and a relatively weak right ventricle located high relative to the apex. The pectinate muscles of the atria are dense, localized closely, the muscles of the first order had a larger diameter and shorter length, were located perpendicular to the longitudinal axis of the appendix, the muscles of the second order had a smaller diameter, but longer, with a well-defined cushion shape. Fleshy trabeculae of the water deer's heart are poorly structured, the pattern is smoothed. The greatest severity of these formations is in the apical region of the left ventricle, on all three surfaces (cranial, caudal and medial), in the area of the papillary muscle - on the wall of the right ventricle. The septomarginal trabeculae of both ventricles are of the tendinous type, there is only the cranial one in the right one, in the left one, there are both cranial and caudal ones. The papillary muscles of the right atrioventricular valve are well expressed. The small papillary muscle is cone-shaped, with one head. Hyparterial one is of complex indefinite shape, with two heads. The papillary muscle is large, of a complex indefinite shape, with three heads. Both papillary muscles of the left ventricle are cylindrical in shape with one head, well developed, located on the wall opposite to the interventricular septum. The valve cusps did not have a clearly defined border between themselves.

The serous membrane of the larynx and trachea was pale gray in color; the vessels did not contain blood. The mucous membrane of the trachea was red-gray in color, moist, and contained a small amount of foamy liquid. The lung was enlarged in volume, lush consistency, pink-red in color, when pressed, the fossa quickly leveled out, the incision surface was dry, the mass of the lungs with the mediastinum and part of the trachea was $0.384 \mathrm{~kg}$. The morphometric characteristics of the lungs of water deer are presented in table 2.

Table 2. Morphometric characteristics of the lungs of a water deer.

\begin{tabular}{|c|c|c|c|c|}
\hline No. & Indicators & Appearance & $\begin{array}{l}\text { Length } \\
\text { (cm) }\end{array}$ & $\begin{array}{l}\text { Width } \\
\text { (cm) }\end{array}$ \\
\hline 1 & Lung & $\begin{array}{l}\text { The right lung is larger in size, has different } \\
\text { shapes and sizes of lobes from the left }\end{array}$ & 24.0 & 20.0 \\
\hline 2 & Right apical lobe & $\begin{array}{l}\text { Square (hammer type) shape with tapered } \\
\text { ridges, attached by a fixed and short } \\
\text { ligament to the trachea } 9.5 \mathrm{~cm} \text { above the } \\
\text { bifurcation }\end{array}$ & 10.0 & 8.0 \\
\hline 3 & Right middle & Triangular shape with rounded edges & 11.0 & 3.5 \\
\hline 4 & Right heart lobe & Triangular elongated shape & 8.5 & 5.0 \\
\hline 5 & $\begin{array}{l}\text { Right } \\
\text { diaphragmatic lobe }\end{array}$ & $\begin{array}{l}\text { Semi-oval shape, beginning at the } \\
\text { bifurcation level. }\end{array}$ & 13.3 & 9.2 \\
\hline 6 & Additional lobe & $\begin{array}{l}\text { Located on the medial side between the } \\
\text { right and left phrenic lobes of the lung } \\
\text { caudal from the bifurcation, flap-shaped, } \\
\text { connected to the right phrenic lobe. }\end{array}$ & 4.5 & 6.5 \\
\hline 7 & Left apical lobe & $\begin{array}{l}\text { Elongated triangular shape, its base is at the } \\
\text { level of bifurcation }\end{array}$ & 9.5 & $\begin{array}{l}5.0 \text { at the } \\
\text { base }\end{array}$ \\
\hline
\end{tabular}




\begin{tabular}{|c|l|l|c|c|}
\hline 8 & Left heart lobe & Elongated triangular shape & 12.0 & $\begin{array}{c}3.5 \text { at the } \\
\text { base }\end{array}$ \\
\hline 9 & $\begin{array}{l}\text { Left diaphragmatic } \\
\text { lobe }\end{array}$ & Semicircular shape & 13.0 & 10.0 \\
\hline
\end{tabular}

Analyzing the presented table 2, we found that the left lung consisted of the apical, cardiac and diaphragmatic lobes, and the right lung consisted of the apical, middle, cardiac, diaphragmatic and accessory lobes.

Under the upper lip of a deer, saber-like curved, weakly wobbling, long-crowned canines of white color, the length of which reached $2.4 \mathrm{~cm}$, and the width at the base of the alveoli $-1.0 \mathrm{~cm}$. The dental formula of a water deer is $\mathrm{I} 0 / 4, \mathrm{C} 1 / 0, \mathrm{P} 3 / 3, \mathrm{M} 3 / 3 \times 2=34$. Lower incisors are relatively small, light gray, in the amount of 8 pieces, including: central incisors-2, narrow base, wide apex; middle inner-2, middle outer-2 and corner teeth -2 , without traces of erasure. The upper incisors were absent; in the anterior part of the upper jaw, the mucous membrane was in the form of a cushion, hard, yellow-gray in color. Posterior teeth (premolars and molars) are not high, brachyodont, light gray, selenodont, with a well-developed tuberous surface, with sharp edges, bifurcation is preserved only from the outer edge of the teeth, there are traces of abrasion from the inner side, lateral surfaces are dark brown.

The liver was located in the right hypochondrium. It was a flat and oval elongated organ, red-brown in color, of moderately dense consistency, with pointed edges. Its length was $20.0 \mathrm{~cm}$, its width was $12.0 \mathrm{~cm}$, and its weight was $0.283 \mathrm{~kg}$. The gate of the liver (porta hepatis) is poorly expressed. The gall bladder was absent. The cranial surface of the liver is smooth and convex, and the caudal surface is concave and has a weakly pronounced lobulation. The ventral margin of the organ is thin. Outside, the organ is covered with a serous membrane, which forms the ligaments of the liver. As a result of the gunshot wound, the liver was torn in some places, soaked in blood, so it was not possible to establish the number of lobes and their sizes.

The paunch is the largest of the forestomaches, it had a rounded shape. The paunch contained a moderately dense consistency consisting of fragments of awns of grass, cereals, horsetail, leaves. The mucous membrane is dotted with keratinized yellow-brown papillae. The content of the honeycomb bag is of a soft consistency of yellow-brown color, the mucous membrane is brown, the cells are poorly expressed. The contents of the manifold are moderately dense and moist, brown in color, the mucous membrane is gray-brown in color, presented in the form of folds (leaves) with keratinized papillae. The abomasum (true stomach) in this deer had the shape of an elongated pear, its contents were brown liquid forage masses, the mucous membrane was gray-pink in color with small folds. The mass of the forestomaches and abomasum with contents is $1.940 \mathrm{~kg}$. Metric characteristics of the forestomaches, abomasum and intestines of water deer are presented in table 3 . Thus, the presence in the water deer of three forestomaches (paunch, honeycomb bag, manifold) and one true stomach (abomasum) indicates that this species belongs to animals with the type of digestion characteristic of ruminants [1].

The omentum and mesentery of the small intestine contained minor fat deposits ranging from bright yellow to light gray. The serous membrane of the duodenal ulcer was grayyellow in color; the bile and pancreatic ducts were located $28.0 \mathrm{~cm}$ caudal from the pylorus.

Table 3. Metric indicators of the intestine of the water deer.

\begin{tabular}{|c|l|c|c|}
\hline No. & Indicators & Appearance & Length (cm) \\
\hline 1 & Paunch & 24.0 & 25.0 \\
\hline 2 & Honeycomb bag & 12.0 & 9.0 \\
\hline 3 & Manifold & 9.5 & 6.0 \\
\hline 4 & Abomasum & 19.5 & 8.0 \\
\hline
\end{tabular}




\begin{tabular}{|c|l|c|c|}
\hline 5 & Duodenal ulcer & 32.0 & 2.4 \\
\hline 6 & Jejunum & 2100.0 & 2.0 \\
\hline 7 & Twisted intestine & 17.0 & 2.3 \\
\hline 8 & Cecum & 42.0 & 3.8 \\
\hline 9 & Colon & 46.0 & 2.5 \\
\hline 10 & Rectum & 32.0 & 2.8 \\
\hline
\end{tabular}

The jejunal loops were located in the right half of the abdominal cavity, suspended on a relatively short mesentery, located around the colon laid in the form of a spiral labyrinth consisting of five centripetal and centrifugal loops on a short mesentery.

In the small intestine, traces of chyme are brown-gray. The mesenteric lymph nodes are ribbon-like, light gray in color.

In the large intestine, there is a small amount of feces of a soft consistency, in the rectum, there are small excrements (nuts), round, black in color. The cecum occupied a large place in the abdominal cavity, the contents were of a semi-liquid consistency, grayyellow in color. The total intestine length of the studied deer is $2.269 \mathrm{~cm}$, while the small intestine was $94.7 \%$, and the large one - only $5.3 \%$ of the total intestinal length. The jejunum is the longest and narrowest, and the widest is the cecum.

In structure, the water deer intestines are identical to those of ruminants.

The pancreas is $31.0 \mathrm{~cm}$ long, light gray in color, flabby consistency.

The left adrenal gland is located at the cranial margin of the kidney, bean-shaped, redbrown in color; the length of the left adrenal gland was $2.4 \mathrm{~cm}$ with a weight of $0.017 \mathrm{~kg}$. The right adrenal gland was destroyed as a result of a gunshot wound.

The spleen is round-triangular in shape, soft consistency, rounded edges, dark red, 17.0 $\mathrm{cm}$ long and $11.0 \mathrm{~cm}$ wide, with a weight of $0.166 \mathrm{~kg}$.

An undamaged left kidney of gray-red color, smooth, single-papillary, heart-shaped, dense consistency was located under the transverse costal processes of 2-4 lumbar vertebrae, mobile. The length of the left kidney is $5.5 \mathrm{~cm}$, width $-3.3 \mathrm{~cm}$, thickness -2.0 $\mathrm{cm}$. The cortical layer is light brown, $0.8 \mathrm{~cm}$ high, the cerebral layer is pink, $1.3 \mathrm{~cm}$ high. One renal pelvis, $0.9 \mathrm{~cm}$ high, passed directly into the ureter. The right kidney, as a result of a gunshot wound, is torn, soaked in blood. The bladder is relatively small, without content, the mucous membrane is pale pink in color.

The genitals are represented by the uterus, paired ovaries and oviducts, vagina and vulva. The uterus is two-horned, without contents, the length of the uterus body is $6.5 \mathrm{~cm}$, the horns are $7.0 \mathrm{~cm}$ long, the ovaries are small $(1.0 \times 1.0 \mathrm{~cm})$, the length of the vagina is $9.0 \mathrm{~cm}$. In the right ovary, there was a single follicle $(0.5 \times 0.5 \mathrm{~cm})$. The mucous membrane of the vulva is light gray color, moderately moist, with well-defined blood vessels.

\section{Conclusions}

We have studied and described the internal organs of the water deer (Hydropotes inermis Swinhoe 1870). This animal is represented by a female, presumably 2-2.5 years old, weighing $19.8 \mathrm{~kg}$, with saber-like canines.

The heart of the studied specimen of water deer is spherical in shape, it is distinguished by a strong left ventricle and a relatively weak right ventricle located high relative to the apex. The lungs of a water deer are identical in shape to the lungs of cattle, but they are much smaller and more pointed in the shape of the apical and heart lobes. The spleen, adrenal glands and liver are identical in shape to those of small ruminants and deer. In accordance with the structure of the gastrointestinal tract, this species of deer belongs to ruminants. The kidney is smooth, single-papillary, which is typical for small ruminants and deer, but has a heart shape, which is observed in horses. 


\section{References}

1. A.I. Akayevsky, Yu.F. Yudichev, S.B. Seleznev, Anatomy of domestic animals (Aquarium-Print, M.,2009)

2. B.G. Vodopyanov, V.O. Salovarov, Determination of the age and sex of hunting animals (Publishing house of ISAA, Irkutsk, 2001)

3. Yu.A. Darman, V.B. Storozhuk, G.A. Sedash, Nature Conservation Research 4(3), 127-129 (2019)

4. G.V. Ivanchuk, Quality of education and innovation in agricultural universities of the Far Eastern Federal District: materials of the regional scientific and methodological conference (Primorsk State Agricultural Academy, Ussuriisk, 2007)

5. N.S. Kukharenko, The postmortem examination technique when working with fallen animals: textbook (DalGAU, Blagoveshchensk, 2011)

6. E.N. Lyubchenko, I.P. Korotkova, G.V. Ivanchuk, et al., Morphometric studies of wild cats of the Far East: textbook (FSBEI HE "Primorsk State Agricultural Academy", Ussuriisk, 2018)

7. V.G. Krivosheev, Terrestrial mammals of the Far East (Nauka, M., 1984)

8. V.E. Sokolov, Taxonomy of mammals. Groups of cetaceans, carnivores, proboscis, hyraxes, sirens, artiodactyls, calluses, equids: textbook (Vysshaya Shkola, M., 1979)

9. P.V. Fomenko, E.N. Lyubchenko, I.P. Korotkova, et al., Zoological journal (2021)

10. M.Yu. Shchelkanov, I.V. Galkina, P.V. Fomenko, et al., Russian journal of criminology 11(1), 146-153 (2017)

11. Y.J. Chen, K.H. Liu, W.L. Chu, Collect. Res. 29, 31-39 (2016)

12. B.J. Kim, Y.S. Lee, Y.S. Park, K.S. Kim, M.S. Min, S.D. Lee, H. Lee, Genes Genet. Syst. 90(1), 59 (2015)

13. H.S. Koh, B.K. Lee, J. Wang, S.W. Heo, K.H. Jang, Biochem. Genet. 47(11-12), 860867 (2009)

14. R. Swinhoe, Proc. Zool. Soc. London 1870, 86-99 (1870) 